\title{
Comparative Efficacy of Serum Creatinine and Microalbuminuria in Detecting Early Renal Injury in Asphyxiated Babies in Calabar, Nigeria
}

\author{
Sunday O. Ochigbo ${ }^{1, *}$, Udo J. Jacob ${ }^{1}$, Anthony C. Nlemadim² and Olaniyo O. Kudirat ${ }^{2}$ \\ ${ }^{1}$ Department of Pediatrics, University of Calabar, Calabar, Nigeria \\ ${ }^{2}$ Department of Pediatrics, University of Calabar Teaching Hospital, Calabar, Nigeria
}

\begin{abstract}
Background: Microalbuminuria and serum creatinine are markers of acute kidney injury. Birth asphyxia is responsible for $50 \%$ of all newborn deaths and acute non-oliguric kidney injury is one of such complications. This study was undertaken to determine the efficacy of serum creatinine and microalbuminuria for the detection of early renal lesion in severely asphyxiated babies in Calabar, Nigeria.

Materials and Method: This prospective cross-sectional investigational study was undertaken among severely asphyxiated babies admitted into the newborn units of the University of Calabar Teaching Hospital (UCTH), Calabar, Nigeria. Standard method for blood collection and determination of urea, electrolytes were used. Micral-test strips were used on samples negative only for albumin after using urine dipstick. Color comparison was done with the standardized color scale on test strip container after 5 minutes.
\end{abstract}

Results: Fifty term newborn babies were enrolled, their serum electrolytes, creatinine and creatinine clearance were essentially normal. Six (12\%) babies had positive microalbuminuria, while $44(88 \%)$ had negative microalbuminuria with specificity and negative predictive values of $100 \%$ and $88 \%$ respectively.

Conclusion: Microalbuminuria was not useful for early detection of acute renal failure in babies with severe birth asphyxia, but further studies are recommended.

Keywords: Micral test strip, Birth Asphyxia, Acute Kidney Injury, APGAR, Newborn.

\section{INTRODUCTION}

Microalbuminuria is an early marker of certain diseases including those affecting the renal system. Creatinine reflects renal filtering capacity which has a lot of reserve, therefore not very sensitive for acute or chronic kidney injury unless the injury is substantial enough to compromise the filtering ability. There is continuous positive relationship between urinary albumin excretion and adverse clinical outcomes [1]. Estimates of the prevalence of acute kidney injury (AKI) vary depending on the definition and setting. Some degree of renal insufficiency is noted in $7.1 \%$ of hospital admissions [2] and in $30 \%$ of patients admitted to an intensive care unit [3]. Most patients with kidney disease are asymptomatic, underlining the need for routine screening of all patients who are at risk for developing kidney disease. For acute kidney diseases that have no specific therapy, accurate understanding of severity of renal dysfunction enhances appropriate chemotherapeutic adjustment, and important prognostic information. The identification of AKI leads to early referral to nephrologist with associated improved outcomes [4]. More importantly,

*Address correspondence to this author at the Department of Pediatrics, University of Calabar, Calabar, Nigeria; Tel: 07063930682;

E-mail: ochigbosunny@gmail.com early detection of $\mathrm{AKI}$ is expected to enhance appropriate intervention.

Plasma creatinine and conventional methods of measurement may be misleading especially in early newborn life. The best way to assure early detection is to measure the levels of the protein (Albumin) in urine using the Micral strip though its reliability in neonate has also been questioned [5]. In normal individuals, the level of albumin in urine should be less than 20 $\mathrm{mg} / 24 \mathrm{hrs}$. When levels fall between 20 and $200 \mathrm{mg} / 24 \mathrm{hrs}$, it indicates significant microalbuminuria thus alerting the physician that albumin is spilling into the urine beyond an acceptable range which indicates a renal injury [6].

The study of microalbuminuria vis a vis serum creatinine as a marker of kidney injury in severely asphyxiated newborn babies has not been undertaken in Calabar, hence the need for the present survey. The diagnostic approach using urine albumin is cheaper and less invasive especially in resources settings.

\section{METHODOLOGY}

This prospective cross sectional study was conducted between April - September 2014 at the University of Calabar Teaching hospital, southern, Nigeria. This is 650 beds tertiary facility which provides 
health care services for adults and children. It has the specialized newborn units with capacity to admit 60 babies. These units, previously described by Udo et al. [7] admit both inborn and outborn neonates. All severely asphyxiated term neonates admitted into the newborn units of the University of Calabar Teaching Hospital (UCTH) during the study period were enrolled.

In this study, severe birth asphyxia was defined as APGAR scores of 3 and below at 5 minutes after birth. Detailed history obtained in respect of each neonate included the age, sex, birth weight, symptoms and signs at delivery, mother's age, duration of labor, place and mode of delivery including other relevant neonatal and maternal history. A thorough physical examination and relevant anthropometric measurements were conducted. Excluded from the study were preterm newborn, babies with fever $\left(\right.$ Temp $\left.>37.5^{\circ} \mathrm{C}\right)$, babies with preexisting renal diseases or congenital renal pathology, and history of antibiotic use.

Standard method for blood collection, determination of urea, creatinine and other electrolytes was used. The serum creatinine clearance was calculated using a simple and reliable formula (modified Schwartz formula) [8]. Urine samples were collected with the use of urine bags, where there was difficulty in collection especially for the female babies; a suprapubic tap was done and urine was collected into pre-labeled universal bottles for analysis. Urinalysis was done for each baby using the Combi-10 multi-strip. Only urine samples negative for albuminuria was further tested for MicroAlbuminuria (MA) using the Micral-test strips (Roche diagnostics Quebec, Canada) [9]. After one minute, the observed color was compared with the test pad inscription "Micral" with the color scale on the test strip container. Comparison of the reaction color with the color scale was also done 5 minutes after the first test as the color is stable for that period. The screening result is positive when at least two of the urine samples produce a reaction color corresponding to $20 \mathrm{mg} / \mathrm{dl}$ albumin (threshold for microalbuminuria) or more. All babies were provided with routine care for birth asphyxia until discharge. The study was terminated if the patient requested for transfer to another health care facility, discharge against medical advice, voluntary withdrawal of consent after initial approval, discharged by the doctor and death of the patient. This study was approved by the ethical committee of the institution prior to commencement.

Data were recorded and standard statistical analysis was performed using SPSS statistical package version 20. Continuous variables were summarized using means, median and ranges as appropriate. Proportions were compared using Chi-square test of significance. A probability ( $P$-value) less than 0.05 was considered statistically significant.

\section{RESULTS}

Fifty (50) infants were enrolled into the study comprising $32(64 \%)$ males and $18(36 \%)$ females with $\mathrm{M} ; \mathrm{F}$ ratio of $1.8: 1$. Most of the male babies were less than 6hours $(34.4 \%)$ of age, while females babies were mostly $>48 \mathrm{hrs}(33.3 \%)$. The mean age of the babies was $30.3 \pm 36.2 \mathrm{hrs}$. The mean ages for males and females were $26.9 \pm 38.2 \mathrm{hrs}$ and $36.4 \pm 32.6 \mathrm{hrs}$ respectively (Table $\mathbf{1}$ ).

Generally, the male neonates had higher anthropometric parameters than the females. The mean weight and Occipitofrontal circumference (OFC) were $3.05 \pm 0.57$ and $34.6 \pm 1.77$ respectively. The mean length for the males was $50.3 \pm 3.51 \mathrm{~cm}$ and females $47.5 \pm 5.0 \mathrm{~cm}$. This was found to be statistically significant $(p$ value $=0.045)$ (Table 2).

The serum electrolytes, creatinine and creatinine clearance were essentially normal for both groups of

Table 1: Demographic characteristics of the study population

\begin{tabular}{|c|c|c|c|}
\hline Age (hrs) & Male (\%) & Females (\%) & Total (\%) \\
\hline \hline$\leq 6$ & $11(34.4)$ & $4(22.2)$ & $15(30)$ \\
\hline$>6 \leq 12$ & $3(9.4)$ & $2(11.1)$ & $5(10)$ \\
\hline$>12-\leq 24$ & $6(18.7)$ & $1(5.5)$ & $7(14)$ \\
\hline$>24-\leq 48$ & $8(25)$ & $5(27.9)$ & $13(26)$ \\
\hline$>48$ & $4(12.5)$ & $6(33.3)$ & $10(20)$ \\
\hline Total & $32(100)$ & $18(100)$ & $50(100)$ \\
\hline
\end{tabular}

Total Mean age $30.3 \pm 36.2 \mathrm{hrs}$

*Mean age $($ males $)=26.9 \pm 38.2 \mathrm{hrs}$.

+Mean age (Females) $36.4 \pm 32$.6hrs. 
Table 2: Age and sex distribution according to anthropometric characteristics

\begin{tabular}{|c|c|c|c|c|c|c|}
\hline Age (hrs) & \multicolumn{2}{|c|}{ Weight (kg) } & \multicolumn{2}{|c|}{ Length (cm) } & \multicolumn{2}{|c|}{ OFC (cm) } \\
\hline$\leq 6$ & $3.9 \pm 1.5$ & $2.79 \pm 0.5$ & $52.4 \pm 3.8$ & $44.3 \pm 11.6$ & $35 \pm 1.4$ & $36.2 \pm 0.29$ \\
\hline$>6-\leq 12$ & $3.55 \pm 0.6$ & 0 & $46.5 \pm 2.1$ & 0 & $35.5 \pm 0.7$ & 0 \\
\hline$>12-\leq 24$ & $2.99 \pm 0.46$ & $2.67 \pm 0.51$ & $50.4 \pm 2.9$ & $49 \pm 3.0$ & $34.7 \pm 1.8$ & $34.3 \pm 1.5$ \\
\hline$>24-\leq 48$ & $2.90 \pm 0.45$ & $3.02 \pm 0.6$ & $50.4 \pm 3.6$ & $46.5 \pm 0.7$ & $34.7 \pm 0.88$ & $33 \pm 0$ \\
\hline Total Mean & $3.15 \pm 0.54$ & $2.86 \pm 0.58$ & $50.3 \pm 3.51$ & $47.5 \pm 5.02$ & $34.89 \pm 1.52$ & $34.14 \pm 2.1$ \\
\hline
\end{tabular}

Mean of all Subjects

Weight - $3.05 \pm 0.57$; Length- 49.3 \pm 4.29 ; OFC $34.6 \pm 1.77$.

*M-males; F-females; hrs - hours.

Table 3: Relationship between Microalbuminuria and serum electrolytes, urea, creatinine and creatinine clearance in the subjects

\begin{tabular}{|c|c|c|c|c|}
\hline Parameter & $\begin{array}{l}\text { MA Positive }(n=50) \\
\text { Mean } \pm S D\end{array}$ & $\begin{array}{c}\text { MA Negative }(n=50) \\
\text { Mean } \pm S D\end{array}$ & $\mathbf{t}$ & p-Value \\
\hline Sodium $(\mathrm{mmol} / \mathrm{l})$ & $133.2 \pm 5.7$ & $134.5 \pm 5.2$ & 0.58 & 0.56 \\
\hline Potassium(mmol/l) & $4.0 \pm 0.47$ & $4.3 \pm 0.8$ & 1.24 & 0.24 \\
\hline Bicarbonate(mmol/l) & $18.3 \pm 3.4$ & $18.1 \pm 3.5$ & -1.71 & 0.87 \\
\hline Chloride $(\mathrm{mmol} / \mathrm{l})$ & $100.3 \pm 2.4$ & $102.6 \pm 6.1$ & 1.68 & 0.12 \\
\hline Urea(mg/dl) & $3.62 \pm 2.15$ & $5.18 \pm 3.04$ & 1.21 & 0.23 \\
\hline S. Creatinine (umol/l) & $100 \pm 7.13$ & $109.3 \pm 25.1$ & 1.83 & 0.08 \\
\hline Creatinine Clearance & $0.21 \pm 0.03$ & $0.22 \pm 0.03$ & 0.95 & 0.35 \\
\hline
\end{tabular}

Table 4: Serum creatinine and Microalbuminuria in the detection of Renal impairment

\begin{tabular}{|c|c|c|c|}
\hline \multirow{2}{*}{ Serum Creatinine $(\mu \mathrm{mol} / \mathrm{l})$} & \multicolumn{2}{|c|}{ Microalbuminuria } & \multirow{2}{*}{ Total } \\
\hline & Yes (\%) & No (\%) & \\
\hline Elevated & 0 & 0 & 0 \\
\hline Normal & $6(12 \%)$ & $44(88 \%)$ & 50 \\
\hline Total & $6(12 \%)$ & $44(88 \%)$ & $50(100 \%)$ \\
\hline
\end{tabular}

babies with and without microalbuminuria. Although babies with negative microalbuminuria had slightly higher values but there is no statistical difference between groups (Table 3 ).

Six babies $(12 \%)$ had microalbuminuria while 44 babies $(88 \%)$ were negative for microalbuminuria. None of the babies showed abnormally high levels of serum creatinine, creatinine clearance or electrolytes. Hence the specificity was $100 \%$, while Negative predictive value was $88 \%$ respectively (Table 4 ).

\section{DISCUSSION}

Birth Asphyxia is a cause of morbidity and mortality worldwide and accounts for $23 \%$ of the 4 million deaths globally [10]. Studies have shown that it is responsible for $50 \%$ of all newborn deaths [10]. Acute renal lesion is a complication of severe birth asphyxia which presents commonly with non-oliguric kidney injury [11, 12].

The biochemical findings of the newborn in the first few days of life are unreliable, though Cuzzolin and colleaques [13] showed no difference in the levels of electrolytes and serum creatinine among low birth weight (LBW), very low birth weight (VLBW), and normal neonates.

None of the growth parameters studied showed any statistically significant difference except the mean length between males and female subjects. This is 
corroborated by Byung et al. [14] who observed the correlation between microalbumin/creatinine ratio with age, height, weight and body surface area among normal Korean children. This is at variance with the findings of Gould MM et al. [15] where the lengths of the babies were inversely proportional to microalbuminuria. More studies with larger sample size are advised in our locale to further evaluate this relationship.

The hyponatraemia and acidosis observed were not unexpected findings in Neonates with severe birth asphyxia. It may be due to the disequilibrium from fractional excretion of sodium probably associated with the effect of rennin Angiotensin system, circulatory catecholamine, atrial natriuitic peptide and prostaglandins. The hyponatraemia observed may be related to the dilutional effect of inappropriate Antidiuretic hormone $(A D H)$ secretion occasionally observed in some severely asphyxiated babies. Hypoxia following birth asphyxia may be the cause of the metabolic acidosis observed in the study. These observed values were not below the critical levels to warrant urgent correction. The slightly high potassium levels noted could be attributed to in vitro hemolysis. This observation is corroborated by Basu et al. [16].

The normal serum creatinine and creatinine clearance observed was not unexpected because creatinine usually remains normal except in severe renal injury. Serum creatinine concentrations may not change until $25-50 \%$ of the kidney function is lost, thus it may take days before a significant rise in serum creatinine. Serum creatinine in the first few days of the neonate's life reflects the mother's and not the infant's renal function. Although, the babies in our study were severely asphyxia at birth none showed clinical or laboratory indication of renal failure. This is at variance with the findings by Aggarawal et al. [17] who observed that the incidence of $\mathrm{AKI}$ in infants with 5 minutes APGAR scores was higher compared to controls. They noted that clinical markers of asphyxia were better predictors of adverse outcomes than were renal function tests.

In view of the zero sensitivity and positive predictive value observed in this study, it signifies that microalbumuniuria when compared with serum creatinine as an early predictor of renal derangement is poor, though none of the patients studied presented with established renal disease. This is similar to the findings by Abbulimhen-lyoha et al. in Benin Nigeria [18-20] amongst patients with sickle cell anemia.
Our result indicated that early detection of acute renal injury using microalbuminuria in severely asphyxiated neonate did not have added value. In addition, the performance of microalbuminuria as a predictor of early renal impairment vis a vis serum creatinine in newborn with severe birth asphyxia is unreliable though more studies with larger sample size are advised.

\section{CONCLUSION}

Microalbuminuria is not useful in early detection of acute renal failure in babies with severe birth asphyxia. Further studies with larger sample size are therefore recommended.

\section{FUNDING}

None.

\section{DECLARATION OF INTEREST}

The authors report that they have no conflict of interest.

\section{ACKNOWLEDGEMENT}

All the consultants, residents and entire nursing staff of the newborn units are acknowleged. The authors are indebted to the parents who consented for their babies to be part of this study.

\section{REFERENCES}

[1] Gerstein HC, Mann JF, Yi Q, et al. Albuminuria and risk of cardiovascular events, death, and heart failure in diabetic and nondiabetic individuals. JAMA 2001; 286: 421-6. http://dx.doi.org/10.1001/jama.286.4.421

[2] Nash K, Hafeez A, Hou S. Hospital-acquired renal insufficiency. Am J Kidney Dis 2002; 39: 930-6. http://dx.doi.org/10.1053/ajkd.2002.32766

[3] Ostermann M, Chang RW. Acute kidney injury in the intensive care unit according to RIFLE. Crit Care Med 2007; 35: 1837-43. http://dx.doi.org/10.1097/01.CCM.0000277041.13090.0A

[4] Tseng CL, Kern EF, Miller DR, et al. Survival benefit of nephrologic care in patients with diabetes mellitus and chronic kidney disease. Arch Intern Med 2008; 168: 55-62. http://dx.doi.org/10.1001/archinternmed.2007.9

[5] Guidelines LMP. Microalbuminuria. [September 2, 2012]; Available from: http://santana0612.files.wordpress.com/ 2009/09/microalb.pdf.

[6] Askenazi DJ, Ambalavanan N, Goldstein SL. Acute kidney injury in critically ill newborns: what do we know? What do we need to learn? Pediatr Nephrol 2009; 24: 265-74. http://dx.doi.org/10.1007/s00467-008-1060-2

[7] Udo JJ, Ntia HU, Anah MU, Eyong KI, Ewa AU, Etuk IS. HIV seroprevalence in children whose mothers were seronegative at antenatal care booking in an immunization centre in Calabar, Nigeria. Pediatr Infect Dis J 2013; 8: 83-6. 
[8] Schwartz GJ, Furth SL. Glomerular filtration rate measurement and estimation in chronic kidney disease. Pediatr Nephrol 2007; 22: 1839-48. http://dx.doi.org/10.1007/s00467-006-0358-1

[9] Roche diagnostics Quebec, Canada. 201 boul ArmandFrappier Laval, QC H7V 4A2,(450) 686-7050 Fax:(450) 6867012.

[10] Lawn J, Shibuya K, Stein C. No cry at birth: global estimates of intrapartum stillbirths and intrapartum-related neonatal deaths. Bull World Health Organ 2005; 83: 409-17.

[11] Gupta BD, Sharma P, Bagla J, Parakh M, Soni JP. Renal failure in asphyxiated neonates. Indian Pediatr 2005; 42: 928-34.

[12] Andreoli SP. Acute renal failure in the newborn. Semin Perinatol 2004; 8: 112-23. http://dx.doi.org/10.1053/j.semperi.2003.11.003

[13] Cuzzolin L, Fanos V, Pinna B, et al. Postnatal renal function in preterm newborns: a role of diseases, drugs and therapeutic interventions. Pediatr Nephrol 2006; 21: 931-8. http://dx.doi.org/10.1007/s00467-006-0118-2

[14] Byung Ok, Sang TL, Sochung C, Kyo S K. Microalbuminuria in normal Korean children. Yonsei Med J 2011; 52: 476-81. http://dx.doi.org/10.3349/ymi.2011.52.3.476
[15] Gould MM, Mohamed-Ali V, Goubet SA, Yudkin JS, Haines AP. Microalbuminuria: associations with height and sex in non-diabetic subjects. BMJ 1993 23; 306: 240-2. http://dx.doi.org/10.1136/bmj.306.6872.240

[16] Basu P, Som S, Das H, Choudhuri N. Electrolyte status in birth asphyxia. Indian J Pediatr 2010; 77: 259-62. http://dx.doi.org/10.1007/s12098-010-0034-0

[17] Aggarwal A, Kumar P, Chowdhary G, Majumdar S, Narang A. Evaluation of renal functions in asphyxiated newborns. $J$ Trop Pediatr 2005; 51: 295-9. http://dx.doi.org/10.1093/tropej/fmi017

[18] Abhulimhen-lyoha IB, Ibadin OM, Ofovwe EG. Comparative usefulness of serum creatinine and microalbuminuria in detecting early renal changes in children with sickle cell anaemia in Benin city. Nig J Paediatr 2009; 36: 1-8.

[19] Eke CB. Microalbuminuria in children with Sickle cell anaemia seen at University of Nigeria Enugu Teaching Hospital; FWACP April 2010.

[20] Solarin AU, Njokanma FO, Kehinde O. Prevalence and clinical correlates of microalbuminuria among children with sickle cell anaemia attending Lagos state University teaching hospital, Ikeja. Afr J Paed Nephrol 2014; 1: 37-45. 